\title{
IMAGENS, NARRATIVAS E AGENCIAMENTO: ENSAIANDO ABORDAGENS TRANSDISCIPLINARES SOBRE REPRESENTAÇÃO, INFÂNCIA E GÉNERO
}

\author{
Elena Brugioni \\ (CEHUM - Universidade do Minho)
}

\section{RESUMO}

A partir dos acontecimentos relacionados com a campanha \#BringBackOur Girls, procura-se esboçar uma reflexão crítica e conceptual pautada por um contraponto entre imagens fotográficas e narrativas escritas, problematizando as práticas de representação do sujeito subalterno e o seu agenciamento. Encarando a intersecção entre infância e género como lugar matricial de uma narrativa subalterna, procura-se reflectir em torno da relação entre sujeito e objecto que as representações - escrita e visuais - da infância subentendem e convocam.

PALAVRAS-CHAVE: Representação, Infância e Género, Literaturas Africanas, Narrativas Visuais.

\section{ABSTRACT}

Considering the events related with the campaign \#BringBackOurGirls, the aim of this article is to draw a critical and conceptual reflection based on a counterpoint between photographic and written narratives, problematizing the practice of representation of the subaltern subject and its agency. Tackling the intersection between gender and childhood as a paradigm of a subaltern narrative, I propose a critical reflection concerning the relationship between subject and object suggested and implied by written and visual representations of childhood.

KEYWORDS: Representation, Childhood and Gender; African Literatures, Visual Narratives. 
A relação infância, género e pós-colonialidade aponta para um conjunto de itinerários críticos e conceptuais de indubitável interesse e actualidade no âmbito de uma reflexão em torno de narrativas e práticas de representação de e sobre África. Embora as questões que se apresentam correspondam a problemáticas diferentes tendo em conta os lugares de enunciação e os sujeitos de sua autoria, a criança nos seus diferentes desdobramentos representativos aponta para um tema conceptualmente definido do que se pode, geral e aproximadamente, designar como "imaginário africano", quer de um ponto de vista das representações culturais endógenas, bem como no que diz respeito ao olhar exógeno sobre o continente.

No que diz respeito às representações literárias, uma reflexão em torno das "narrativas da infância" proporciona uma articulação crítica de amplo fôlego relativamente a um contraponto entre representações que se situam em contextos diferenciados, bem como num plano teórico e conceptual específico, convocando de imediato a relação entre narrativa, história e sujeito, e configurando a infância, na sua articulação com o género, como um lugar onde narrativa e representação são pautadas por uma dimensão de subalternidade, sem dúvida, paradigmática.

Uma primeira aporia que se coloca na relação entre infância e representação levanta a questão da experiência e do sujeito, configurando a criança nas literaturas africanas como um lugar literário onde a relação entre experiência e narração torna-se complexa, e onde o agenciamento constitui um aspecto crucial desta relação. Neste sentido, as representações e as narrativas sobre a infância colocam uma problemática ulterior, convocando a relação entre arte e realidade e proporcionando, deste modo, uma reflexão que aponta para a iminência da representação artística - escrita, visual ou performativa - e, logo, os seu significado no(s) horizonte(s) de recepção contemporâneo(s).

Procurando desenvolver uma reflexão alargada que se fundamenta numa abordagem transdisciplinar, pautada por um contraponto entre narrativas e representações de diferente natureza, gostaria de começar esta minha reflexão abordando o recente acontecimento das adolescentes raptadas pelo grupo terrorista Boko Haram, e a sucessiva campanha de sensibilização promovida, a nível mundial, nas redes sociais, e apoiada por um grande número de figuras públicas, meios de informação, associações e organizações não governamentais em escala global. O caso da campanha \#BringBackOurGirls [levem de volta as nossas raparigas] constitui, com efeito, um interessante acontecimento do ponto de vista da utilização e do agenciamento de representações, neste caso de natureza visual, no que concerne a sujeitos específicos - tais como crianças e adolescentes - em contextos socioculturais diferenciados, apontando para uma problemática relevante que diz respeito à relação entre representação e instâncias de recepção.

A campanha surge como acção de sensibilização do governo nigeriano e da comunidade internacional para que se tomem as devidas ini- 
ciativas em vista do resgate das raparigas raptadas na Nigéria. Obedecendo aos padrões comunicativos das campanhas que caracterizam as redes sociais, onde as imagens desempenham uma função crucial no que concerne à empatia que se pretende incutir no público, a acção de sensibilização, que começa por iniciativa de um privado cidadão nigeriano, inicia a circular na rede, especialmente nos social networks, através de imagens que representam raparigas "africanas" que, a priori, representariam as adolescentes raptadas, dando um "rosto" às vitimas do acontecimento.

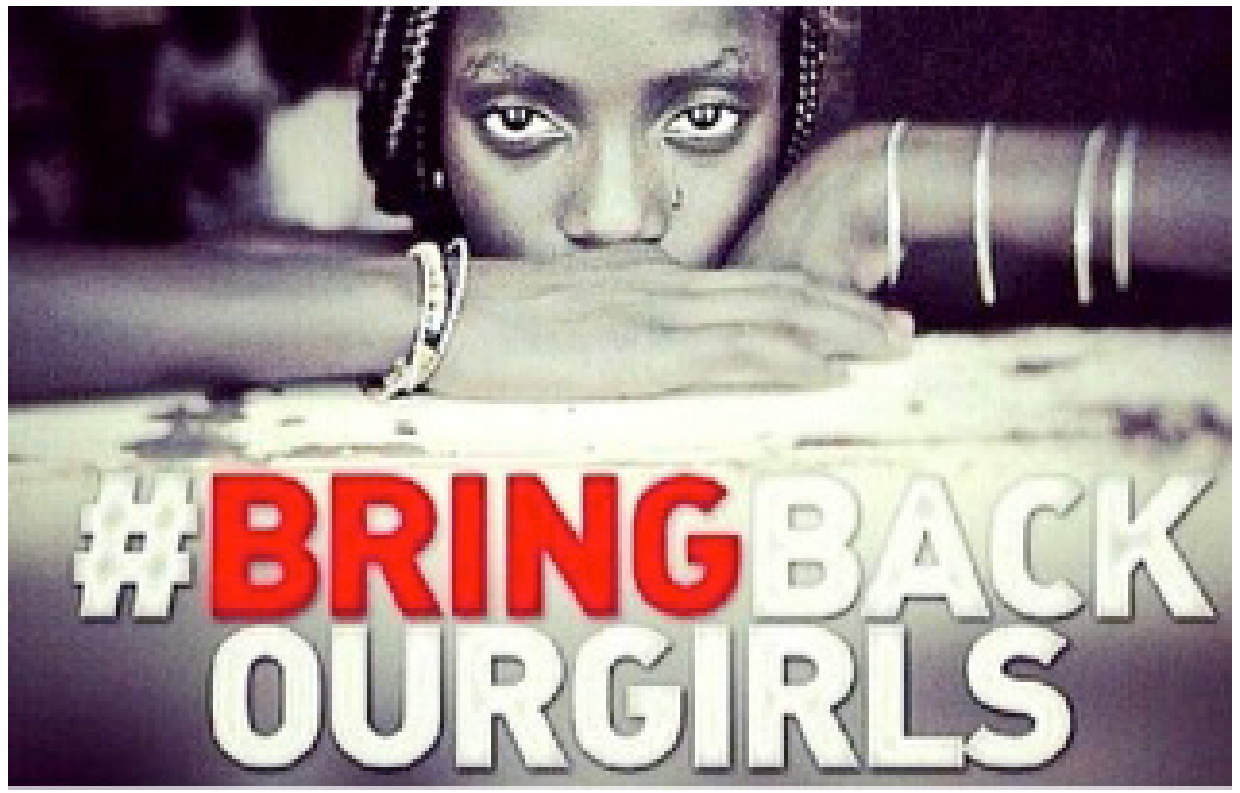

Fig. 1. Imagem utilizada para a campanha \#BringBackOurGirls

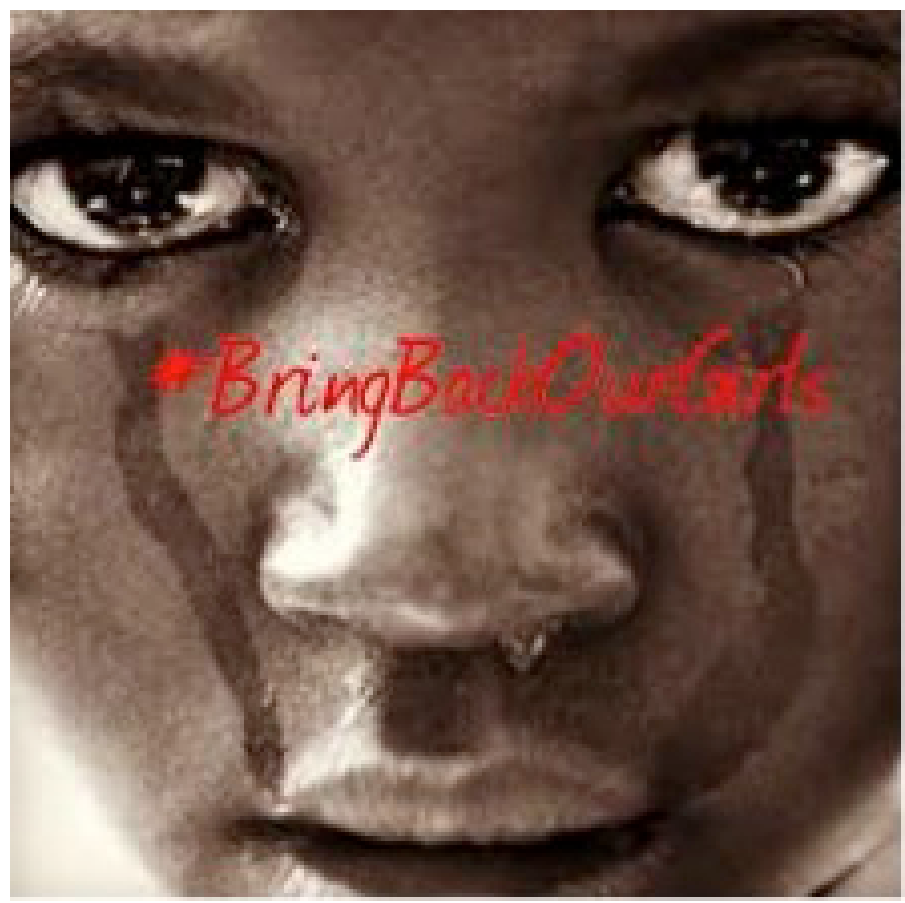

Fig. 2. Imagem utilizada para a campanha \#BringBackOurGirls 
A campanha é disseminada nas redes sociais e em vários meios de comunicação, que, dada a gravidade do acontecimento, reagem de imediato ao apelo, procurando, deste modo, contribuir para fazer pressões sobre o governo nigeriano que, por outro lado, demora em tomar iniciativas para a resolução da situação. Contudo, as imagens utilizadas na campanha suscitam, de imediato, perplexidades, sobretudo nos circuitos editoriais mais ligados ao mundo do fotojornalismo e nos meios de comunicação dos Estados Unidos, tratando-se de imagens de autoria da fotógrafa Ami Vitale e pertencentes a diferentes reportagens desenvolvidas pela autora na Guiné Bissau em diversas ocasiões, entre 1998 e 2011. ${ }^{1}$ A Fundação com que Vitale colabora, Alexia Foundation, alerta a fotógrafa que, de imediato, entra em contacto com os promotores da campanha, denunciando a apropriação e pedindo que se respeite a identidade das pessoas nas fotografias, retirando as imagens das redes sociais. As razões que suscitam a reação da fotógrafa não são evidentemente relacionadas com a utilidade da campanha de sensibilização ou, ainda, com a apropriação de imagens protegidas por direitos de autor, mas prendem-se, em primeiro lugar, com a utilização de fotografias que retratam sujeitos reais, crianças e adolescentes com que Ami Vitale trabalhou para desenvolver as suas reportagens e, logo, que não estão de algum modo relacionadas com o rapto acontecido na Nigéria, o que aponta, de imediato, para um evidente caso de usurpação de identidade. Com efeito, os sujeitos retratados nas imagens são raparigas reais, cujos nomes e histórias acompanham as fotografias das reportagens, não tendo nenhuma ligação com o caso das estudantes raptadas para o qual a campanha de sensibilização \#BringBackOurGirls surge.

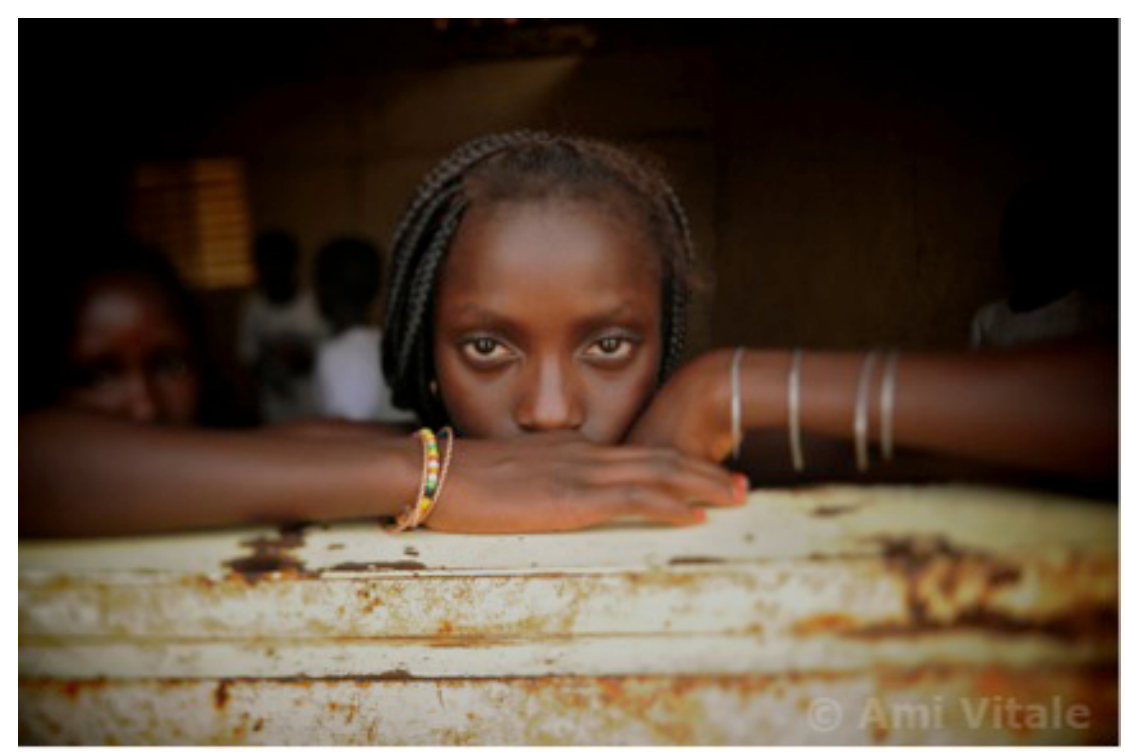

Fig 3. Imagem original da reportagem de autoria de Ami Vitale na Guiné Bissau. Na explicação da Imagem, lê-se: Jenabu, 13 anos, espera pela sua professora na sua escola na Guiné Bissau. Maio 2011.

Ami Vitale / Alexia Foundation

http://www.alexiafoundation.org/stories/AmiVitale; http://www.amivitale.com) 


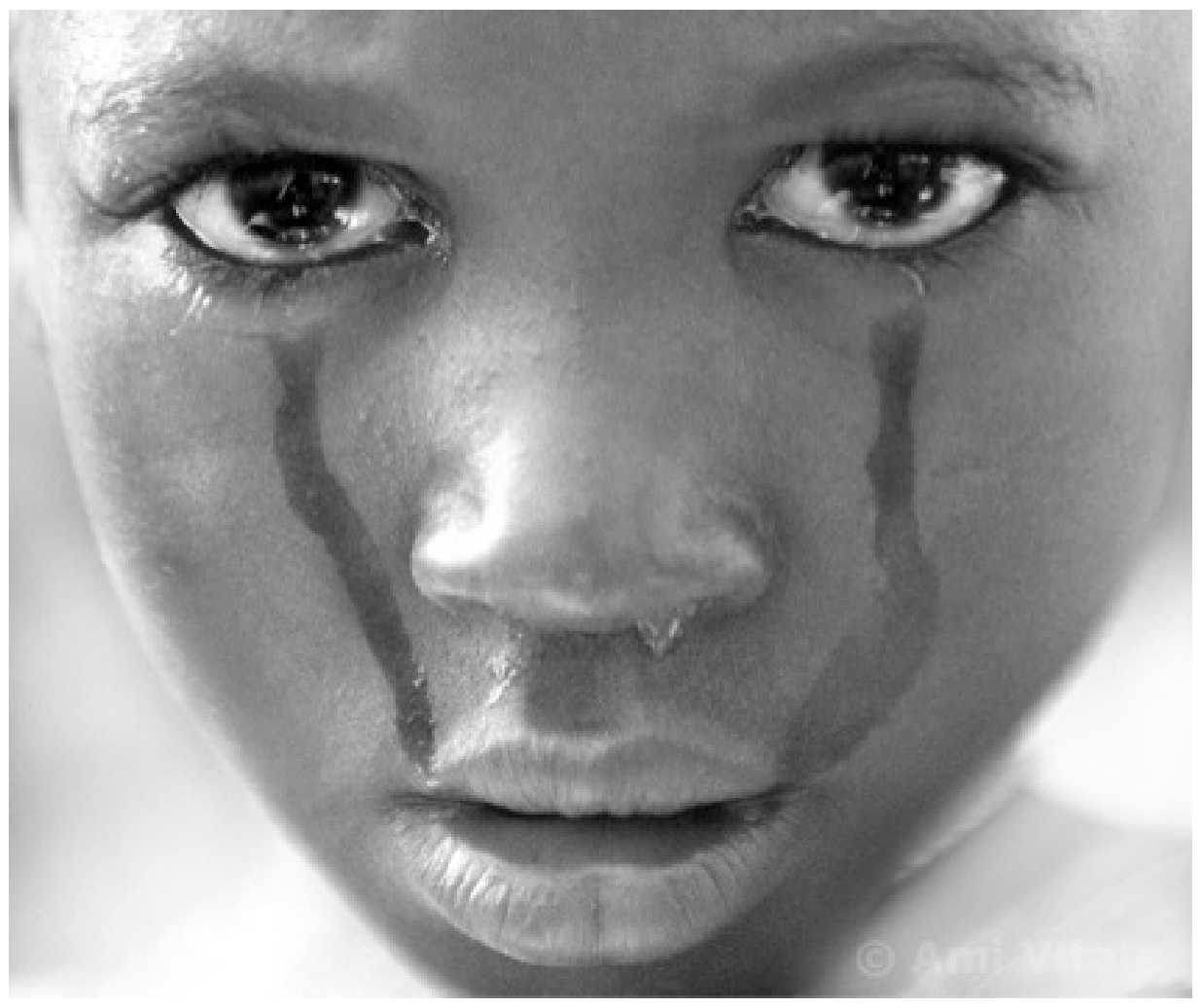

Fig. 4. Imagem original da reportagem de autoria de Ami Vitale na Guiné Bissau. Na explicação da Imagem, lê-se: Awa, 5 anos, chora depois de ter sido circuncisa.

Ami Vitale /Alexia Foundation

http://www.alexiafoundation.org/stories/AmiVitale; http://www.amivitale.com

A situação obriga a fotógrafa a uma acção perante a falsificação das imagens, prestando declarações públicas em entrevistas e em jornais não apenas nos Estados Unidos, e salientando deste modo um conjunto de questões que tocam os aspectos morais e éticos desta apropriação, e convidando a uma reflexão em torno do significado e do agenciamento destas imagens. A preocupação da autora prende-se, em primeiro lugar, com a traição de um compromisso ético que se estabelece entre o fotógrafo e o sujeito das suas imagens, e especialmente na usurpação de imagens que se referem a sujeitos reias, colocando um conjunto de aspectos e questões que são particularmente relevantes no âmbito da reflexão que me proponho desenvolver neste ensaio.

Numa entrevista publicada no blog do New York Times, Lens, ${ }^{2}$ Ami Vitale afirma:

Havia três fotos que foram retirada do meu site ou do site da Alexia Foundation, e alguém fez destas imagens o rosto da campanha. Mas estas fotos não têm nada a ver com as raparigas raptadas, vitimas de tráfico sexual. Há muitas situações em que eu fico zangada quando as pessoas utilizam as minhas fotos sem autorização, mas este não é o caso. Apoio 
completamente a campanha e faria qualquer coisa para chamar a atenção para esta situação. É uma bela campanha que mostra o poder das redes sociais. Mas esta de que estou a falar é uma questão diferente. Trata-se de um caso de falsa representação. Estas fotos não têm nada a ver com as raparigas que foram raptadas. Estas são raparigas da Guiné-Bissau, e a história que eu quis contar foi sobre algo completamente diferente. Elas não têm nada a ver com os terríveis raptos. Pense, por exemplo, em qual seria a sua reação em ver as fotografias da sua filha, utilizadas em todo o mundo, como rosto do tráfico sexual? Estas raparigas nunca foram raptadas, nunca foram vitimas de tráfico sexual. E esta chama-se falsa representação. Eu sei quem são estas raparigas, conheço as suas famílias. Creio que qualquer pessoa ficaria muito zangada em ver o rosto da sua filha divulgado pelo mundo e associado a um acontecimento terrível como este. (VITALE, 2014, sublinhados meus) $)^{3}$

As questões levantadas pela fotógrafa apontam para um conjunto de problemáticas cruciais no que concerne às práticas de representação, neste caso específico, as narrativas visuais numa situação contextual cuja especificidade proporciona uma reflexão teórica que se prende com a relação entre representação, agenciamento das imagens e identidade do sujeito onde o contraponto entre narrativas escritas e visuais se torna particularmente produtiva. Aliás, a fotografia de um sujeito real cuja subalternidade é, neste sentido, paradigmática, torna-se exemplar na medida em que é pensada fora do contexto da campanha de sensibilização, situando o acontecimento numa dimensão privada - como afirma a fotógrafa, o ver as próprias filhas como rostos de um acontecimento desta natureza - e tornando evidente o paradoxo e as implicações a nível público e privado dos sujeitos em questão.

Em primeiro lugar sobressai a questão da apropriação da imagem de uma criança cuja identidade é defraudada para responder aos critérios da comunicação nas redes sociais, apontando para um paradoxo pragmático e conceptual, a meu ver, significativo. É usurpando Awa e Jenabu da sua identidade - e das suas histórias - que a causa das adolescentes nigerianas raptadas ganha ressonância nas redes sociais e nos medias, apontando para um processo onde a representação e as suas potencialidades políticas e comunicativas mostram uma ambivalência complexa e simultaneamente paradoxal.

O intuito da reportagem fotográfica desenvolvida por Ami Vitale corresponde à urgência de atribuir uma subjectividade - "dar um rosto" (VITALE, 2014) - às histórias destas adolescentes, mostrando aspectos das suas vivências que frequentemente o olhar sobre o continente africano silencia. Aliás, a reportagem no seu todo foca os diferentes aspectos da infância destas crianças em diferentes contextos da Guiné Bissau, apontando para a edificação de uma narrativa que é, antes de mais, uma representação que visa desconstruir "a história única" (ADICHIE, 2009) das mulheres no continente africano. Neste sentido a própria fotógrafa, afirma: 
Queria dar um rosto humano ao conflicto. Mas quando cheguei ai [em Guiné Bissau] a minha história mudou. Porque me apercebi como África é geralmente representada nos meios de comunicação social e de massa: guerra, fome ou outras história muito similares a esta do rapto. O que se vê são horrores ou o seu contrário, os maravilhosos safaris e os animais exóticos. E não há nada no meio. Portanto é irónico que a história que eu queria contar pertence a aquele mundo bonito que fica no meio destas duas realidades. Porque nunca contamos as histórias que mostram a dignidade e a resiliência destas pessoas? E é por causa disso que me sinto tão enraivecida por esta situação, porque estava a mostrar estas crianças não como víctimas. Utilizar estas imagens e mostra-las como víctimas não é verídico. A história que eu quis contar com as minhas fotografias era uma história de esperança. (Vitale, 2014) ${ }^{4}$

Do ponto de vista dos sujeitos retratados nas imagens, a utilização destas fotografias para a campanha desubjectiviza as crianças que nelas são retratadas, defraudando a sua identidade e história, e transformando estes dois rostos em símbolos de um acontecimento de grande gravidade mas que, ao mesmo tempo, não tem qualquer relação com as imagens em questão. A atribuição de um rosto às adolescentes nigerianas, que na "narrativa" disseminada nas redes sociais e nos meios de informação são anónimas, através da usurpação da identidade de outras raparigas guineenses subverte de forma paradoxal o agenciamento das fotografias de Awa e Jenabu, apontando para uma problemática complexa que diz respeito à representação do sujeito e do seu significado num horizonte de recepção alargado.

Aliás, observando as fotografias de Awa e Jenabu na perspectivas de uma análise visual propriamente dita, torna-se evidente o agenciamento que as imagens proporcionam, tornando paradoxal a sua utilização numa circunstância que implica a associação das imagens de Ami Vitale com a identidade das adolescentes raptadas na Nigéria, tornando o próprio meio de representação, neste caso a fotografia e a sua fruição, como uma prática de representação que subverte o objectivo preposto pelo seu autor, e determinando o surgir e o disseminar-se de um estereótipo representacional, cujas implicações são significativas para os sujeitos que as imagens retratam. Tendo em conta a especificidade deste acontecimento torna-se imediata uma relação entre os sujeitos da contrafação das imagens e o específico do contexto africano, apontando para uma reflexão em torno do olhar sobre África e, sobretudo, em relação ao que tem sido a representação do sujeito e do contexto africano no horizonte de recepção ocidental. A este propósito, na sua reflexão em torno da representação da violência na fotografia contemporânea, Susan Sontang no ensaio Regarding the Pain of Others (2003), afirma:

Em geral, os corpos gravemente feridos que as fotografias publicadas nos mostram pertencem a asiáticos ou africanos. Trata-se de um hábito jornalístico que herda a praxis secu- 
lar de mostrar seres humanos exóticos - isto é, colonizados: desde o século XVI até o principio do século XX, africanos e habitantes de remotos países asiáticos foram exibidos como animais de um zoo nas exposições etnológicas de Londres, Paris e outras capitais europeias.

[...]

A exibição fotográfica das crueldades afligidas a indivíduos de pele mais escura em países exóticos dá continuidade a este género de oferta, ignorando as considerações que desencorajam comportamentos similares quando as víctimas da violência são nossas, pois o outro, ainda que não seja inimigo, é considerado só como alguém de se ver, e não alguém (como nós) que vê. (SONTAG, 2003, p. 71, tradução minha) $)^{5}$

Embora não se tratando de representação da violência e realçando o ponto central relativo ao facto de que não é o olhar da fotógrafa que opera a "traição" das imagens, mas sim a sua utilização por parte do público, a questão apontada por Susan Sontag é particularmente significativa no específico deste acontecimento, focando a dimensão do "outro" - não branco, não ocidental - como sujeito historicamente privilegiado de um olhar que, como afirma ainda Sontag, é "pornográfico" (2003), e encarando a "alteridade" como elemento fundamental para a suspensão do compromisso ético e moral que deveria estabelecer-se entre representação, público e horizonte de recepção.

Em suma, a usurpação identitária que a utilização dos rostos de Awa e Jenabu na campanha de sensibilização contra o rapto tem operado, é facultada pela alteridade dos sujeitos retratados nas fotografias, duas crianças negras, cuja verosimilhança - racial - lhes retira o direito a uma representação pautada pelos critérios morais e éticos imprescindíveis se os sujeitos em questão fossem, por exemplo, duas crianças brancas e ocidentais. Remetendo para o estereótipo de origem colonial pautado pela ideologia de que o ser humano negro não é um sujeito individual mas sim um elemento indistinto de uma massa populacional alheia à humanidade ocidental - o outro -, este acontecimento oferece a possibilidade de um contraponto significativo entre práticas de representação distintas e, simultaneamente, complementares tal como as narrativas fotográficas e as escritas. A este propósito, tal como salienta a fotógrafa Ami Vitale relativamente à representação que pauta a sua narrativa fotográfica, a literatura africana contemporânea que se debruça sobre a dimensão da infância na sua intersecção com o género, é pautada, em primeiro lugar, pela urgência de individualização da criança nos diferentes contextos sociais e culturais africanos, apontando para uma perspectiva crítica e conceptual onde a infância se configura como um lugar representacional e narrativo pautado por uma relação crucial e irresolúvel com a "alteridade".

Por outras palavras, o romance africano protagonizado por crianças, quer quando a infância corresponde a uma metaforização do "processo de concepção e de 'imaginação da nação"' (DUTRA, 2012, p. 230), ${ }^{6}$ quer 
quando constitui uma narrativa pautada pelas problemáticas sociais, políticas e culturais das crianças no continente africano, ${ }^{7}$ aponta inevitavelmente por uma relação ambígua entre representação e experiência, história e subjectividade configurando a infância como um lugar literário matricial para a problematização das práticas de "narração da nação" (BHABHA, 1991), bem como o elemento paradigmático de uma narrativa forçosamente "subalterna" (SPIVAK, 1998; 2009), em que a relação entre sujeito e o agenciamento se torna central. É esta, porventura, uma das razões que concorrem à definição da infância e da criança como "motivo e tema" central nas literaturas africanas, apontando para uma ambiguidade conceptual de indubitável interesse crítico.

Observando, por exemplo, a obra literária de alguns dos autores mais consagrados das chamadas literaturas africanas contemporâneas, a infância desempenha uma função matricial no que concerne a um conjunto de problematizações críticas que se prendem, por exemplo, com a narração da nação pós-colonial, englobando categorias críticas específicas tais como o Bildungsroman e a Autobiografia, e instituindo a infância como a fase mais significativa da vida humana ou, melhor, como signo de uma narrativa que procura o seu significado mais no futuro de que no passado (MORETTI, 1999). Neste sentido, são multíplices as reflexões que no âmbito da crítica às literaturas africanas se debruçam sobre estes aspectos e as suas articulações teóricas, configurando a infância como um lugar crítico seminal na produção, bem como na recepção às literaturas africanas contemporâneas. À semelhança do contexto europeu, a emergência do romance de formação africano parece surgir correspondendo a momentos e situações de grandes transformações políticas, sociais e culturais (AMOKO, 2009, p. 200) em que a indefinição que caracteriza a transição é reconduzível às transformações determinadas pela "situação colonial" (BALANDIER, 1951). Dentro de um corpus, sem dúvida, vasto e diferenciado, produzido por autores de diferentes origens e tradições culturais e literárias, o Buildungsroman africano parece ilustrar através da infância os desafios colocados pela pós-colonialidade, onde a intersecção entre histórias públicas - História - e privadas - memórias e testemunhos - configura-se como uma estratégia narrativa e de representação crucial para (re)pensar o "futuro do passado" (KOSELLECK, 1996). A este propósito, romances como Boyhood de John M. Coetzee (1997), Nervous Conditions de Tsitsi Dangaremba (1989), Paradise de Abdulrazak Gurnah (1994), The In-Between World of Vikram Lall de M.G. Vassanji (2003), entre muitos outros, configuram a infância como momento seminal para articular a relação entre passado, presente e futuro, propondo uma intersecção entre narrativas privadas - frequentemente de carácter autobiográfico - e histórias públicas, em que a relação entre experiência e objectividade (SARLO, 2005) se torna central.

No que diz respeito às literaturas africanas de língua portuguesa, autores como Luandino Vieira, Manuel Rui, Ondjaki, Pepetela, João Paulo Borges Coelho, Mia Couto e Ungulani Ba Ka Khosa, entre muitos outros, 
apontam para um corpus significativo onde a infância constitui um tema matricial (DUTRA, 2012) que, em geral, metaforiza, parafraseando Laura Padilha, um passado, só em parte segmentado por diferenças de classe e raça, e um futuro pautado pela confiança na reconstrução do corpo histórico fragmentado (PADILHA, 2002).

No entanto, no âmbito da reflexão que me proponho esboçar neste ensaio, a questão prende-se, em primeiro lugar, com as representações literárias que articulam a infância e o género dentro de uma problematização social e cultural situada, procurando uma intersecção entre representação e problemáticas socioculturais contemporâneas que constituem aquilo que Dominic Thomas define como "temas emergentes" (2009) das literaturas africanas contemporâneas. Neste sentido, as problemáticas vivenciadas pelas crianças em contextos e situações específicas, tais como as crianças-soldados, a exploração da prostituição infantil, o tráfico sexual, entre outros, constituem temas de grande actualidade e problematicidade que a representação literária contemporânea africana aborda de forma situada, apontando para uma articulação significativa entre representação literárias e problemáticas sociais. Todavia, tal como no caso da apropriação das imagens de Ami Vitale, é no horizonte de recepção que este tipo de narrativas e representações podem apontar para problemáticas, a meu ver, significativas, proporcionando o surgir de um novo estereótipo que, antes de mais, desubjectiviza a infância em contextos sociais e culturais específicos, transformando-a num lugar estético que proporciona novas modalidades de exotização de África e das suas diferentes realidades. Aliás, o grande número de romances que, nos últimos anos, tem vindo a surgir relacionados com a temática da infância, principalmente na sua intersecção com o género, sobretudo em autores africanos de língua inglesa e francesa aponta para o configurar-se de um “(sub)género" literário de grande interesse, sugerindo, de um ponto de vista crítico, o surgir de uma problematização relevante no que concerne às práticas de representação e ao seu horizonte de recepção. Com efeito, diferentemente das literaturas africanas de língua portuguesa onde o tema da infância parece sobretudo relacionado com o Buildungsroman e com o processo de imaginação da nação (DUTRA, 2012), nas novas gerações de escritores africanos de língua inglesa e francesa - "os filhos da pós-colónia" segundo a definição de Abdourahman A. Waberi (1998) -, o género surge de forma significativa, apontando para uma representação literária que se debruça sobre as questões sociais e culturais da contemporaneidade, configurando a infância nas suas diversas intersecções como um lugar matricial das novas vozes das literaturas africanas contemporâneas. Penso, por exemplo em autores cuja presença nos circuitos editoriais hegemónicos parece particularmente significativa, tais como, Chimamanda Ngozi Adichie, Fatou Diome, Leonora Miano, NoViolet Bulawayo, entre muitos outros, cujas obras literárias convocam o tema da infância em articulação com problemáticas sociais, políticas e culturais específicas e da actualidade, apontando para algumas ambiguidades no que 
concerne às instâncias de recepção e, nomeadamente, à relação que se estabelece entre representação artística e realidade. Na impossibilidade de me deter de uma forma pormenorizada nas diversas questões que diferentes autores e textos colocam, gostaria apenas de esboçar algumas reflexões, em jeito de conclusão, apontando para um conjunto de hipóteses epistemológicas e conceptuais que surgem através do contraponto entre o caso das fotografias utilizadas na campanha \#BringBackOurGirls e obras literárias contemporâneas nas quais o tema da infância convoca problemáticas da actualidade, propondo narrativas que configuram a infância como tema central da representação. A este propósito, é no horizonte de recepção que a problemática do agenciamento se torna particularmente relevante apontando para aquilo que vem sendo definido como "horizonte de expectativas" (JAUSS, 1990). Aliás, obedecendo a uma lógica de desubjectivização que aponta para as mesmas dinâmicas que têm caracterizado a usurpação das imagens de Awa e Jenabu, a literatura africana contemporânea que "ilustra e questiona" as diferentes problemáticas da infância, no que diz respeito a sua recepção, sobretudo em instâncias de recepção "ocidentais" e por via de uma legitimação determinada pelos circuitos editorais hegemónicos, pode concorrer para a criação de um possível estereótipo representacional (BHABHA, 1994) sobre o continente africano, configurando-se como uma nova narrativa do "exótico pós-colonial" (HUGGAN, 2001). A este propósito é, porventura, emblemático o caso da estreia literária da escritora zimbabueana NoViolet Bulawayo cuja obra, We Need New Names (2013), foi finalista do prestigioso prémio literário Booker Prize, suscitando, apesar do seu indiscutível valor estético especialmente tratando-se do primeiro romance publicado pela jovem autora, algumas perplexidades críticas no que se refere à representação de uma África "em negativo" através das histórias de um grupo de crianças que ilustram as diversas problemáticas sociais, culturais e políticas de um continente todavia "nas trevas". A este propósito, na recensão publicada no The Guardian de autoria de Helon Habila, le-se:

O mundo é um lugar sombrio e feio, e muita desta bruteza e injustiça está presente em África, mas não se pede à literatura para confirmar isso. As notícias nos medias já são suficientes. O que se pede à literatura é ter a capacidade de nos levar para além dos títulos que aparecem nos medias. $\left(\right.$ HABILA, 2013) ${ }^{8}$

A recensão, focando um conjunto de questões relacionadas com os horizontes de expectativas e os circuitos editorais britânicos, coloca uma problematização, a meu ver central, que convoca de imediato a relação entre arte - literatura - e realidade - contextos políticos e sociais -, atribuindo à representação literária uma dimensão que deveria ir além de uma matriz meramente documental e colocando, implicitamente, a problemática da relação entre estético e político (RANCIERE, 2005). Por outras palavras, a representação corre, deste modo, o risco de reproduzir uma narrativa "estabelecida", sobretudo nos meios de comunicação, que corresponde ao 
que tem vindo a ser definido como "história única" (ADICHIE, 2009), proporcionando um conjunto de questões que apontam para uma problematização complexa no que concerne às praticas de representação - escritas ou visuais - e o horizonte de expectativa e recepção em que se inscrevem, e sugerindo uma reflexão situada que obriga a repensar o significado das representações e o seu agenciamento no que tem vindo a ser definido como "sociedade sem relato" (CANCLINI, 2012).

\section{REFERÊNCIAS BIBLIOGRÁFICAS}

ADICHIE, Chimamanda Ngozi. The Danger of a Single Story. TED GLOBAL 2009, 2009. (Disponível em http://www.youtube.com/ watch?v=D9Ihs241zeg. Acessado em: Outubro 2012]

AMOKO, Apollo. Autibiography and Buildungsroman in African literature. In: IRELE, Abiola F. (ed.). The Cambridge Companion to the African Novel. Cambridge: Cambridge University Press, 2009, pp. 195-208.

BALANDIER, George. La situation coloniale: Approche théorique. Cahiers internationaux de sociologie 11, 51, 44-79, 1951.

BHABHA, Homi K. The Location of Culture. London; New York: Routledge, 1994.

Nation and Narration. London; New York: Routledge, 1990.

BULAWAYO, NoViolet. We Need New Names. London: Chatto e Windus, 2013.

CANCLINI, Néstor García. A sociedade sem relato. Antropologia e Estética da Iminência. São Paulo: EdUSP, 2012.

COETZEE, John M. Boyhood: Scenes from Provincial Life. London: Secker \& Warburg, 1997.

DANGAREMBA, Tsitsi. Nervous Conditions. Seattle: The Seal Press, 1989.

DUTRA, Robson. A Infância, a Guerra e a Nação. In: BRUGIONI, Elena; PASSOS, Joana; SARABANDO, Andreia; SILVA, Marie-Manuelle (Orgs.). Itinerâncias. Percursos e Representações da Pós-colonialidade | Journeys. Postcolonial Trajectories and Representations. Vila Nova de Famalição: Húmus Ediçoes, 2012, p. 229-242.

GURNAH, Abdulrazak. Paradise. London: Hamish Hamilton, 1994.

HABILA, Helon. We Need New Names by NoViolet Bulawayo - review. The Guardian. Londres, 20 de Junho de 2013. Disponível em: http:// www.theguardian.com/books/2013/jun/20/need-new-names-bulawayoreview Acessado em: 30 de Maio 2014. 
HUGGAN, Graham. The Postcolonial Exotic. Marketing the Margins. London/NY: Routledge, 2001.

JAUSS, Hans Robert. Esperienza estetica ed esperienza letteraria, III. Estetica e interpretazione letteraria. Genova: Marietti, 1990.

KOSELLECK, Reinhart. Il Vocabolario della Modernità. Bologna: Il Mulino, 1996.

Futuro passato. Per una semantica dei temi storici. Genova, Marietti, 2009.

MORETTI, Franco. Il Romanzo di Formazione. Torino: Einaudi, 1999.

PADILHA, Laura Cavalcante. Novos Pactos, Outras Ficções. Lisboa: Novo Imbondeiro, 2002.

SARLO, Beatriz. Tiempo Pasado: Cultura de la Memoria y Giro Subjetivo - Una Discusión. Buenos Aires: Siglo Veintiuno Editores, 2005.

SONTAG, Susan. Davanti al dolore degli altri. Milano: Oscar Mondadori, 2003.

SPIVAK, Gayatry C. A Critique of Postcolonial Reason: Toward a History of the Vanishing Present. Harvard: Harvard University Press, 1999

Can the Subaltern Speak?. In: NELSON, Cary; GROSSBERG, Lawrence (Eds.) Marxism and the interpretation of Culture. London: Mcmillan, 1988.

RANCIÈRE, Jacques. A partilha do sensível: estética e política. São Paulo, 34 Editora, 2005.

THOMAS, Dominic. New voices, Emerging themes. In: IRELE, Abiola F. (Ed) The Cambridge Companion to the African Novel. Cambridge: Cambridge University Press, 2009, p. 227-242.

VASSANJI, M.G. The In-Between World of Vikram Lall. London: Canongate, 2003.

VITALE, Ami. The Real Story about the wrong photos in \#BringBackOurGirls. Lens blog/New York Times. Disponível em: http://lens.blogs. nytimes.com/2014/05/08/the-real-story-about-the-wrong-photos-inbringbackourgirls/?_php=true\&_type=blogs\&_r=0. Acessado em: 15 de Maio 2014.

WABERI, Abdourahman A. Les Enfants de la postcolonie: esquisse d'un nouvelle génération d'écrivain francopnhones d'Afrique noire. Notre Librarie, 135, p. 8-15, 1998. 


\section{AGRADECIMENTOS}

O meu sincero agradecimento às organizadoras deste número da revista ABRIL, Simone Pereira Schmidt e Renata Flavia da Silva, pela confiança e a oportunidade de participar nesta publicação. Um Agradecimento especial à Ami Vitale por ter autorizado a reprodução das suas fotografias neste ensaio e pela sua grande disponibilidade.

\section{NOTAS}

1 Relativamente ao trabalho fotografico de Ami Vitale e às reportagens efectuadas na Guiné Bissau veja-se: http://www.amivitale.com e http://www.alexiafoundation.org/stories/ AmiVitale

2 A entrevista conduzida por James Estrin a Ami Vitale, "The Real Story about the wrong photos in \#BringBackOurGirls” encontra-se publicada no blog Lens - New York Times -, e está disponivel em: http://lens.blogs.nytimes.com/2014/05/08/the-real-story-about-the-wrong-photos-in-bringbackourgirls/?_php=true\&_type=blogs\&_r=0. Acessado em:15 de Maio 2014.

3 Citação no original: “There were three photos that were taken from either my website or the Alexia Foundation website, and someone made these images the face of the campaign. But these photos had nothing to do with the girls who were kidnapped and sexually trafficked. There are many times when I get upset when people take my photos without permission, but this isn't about that. I support the campaign completely and I would do anything to bring attention to the situation. It's a beautiful campaign that shows the power of social media. This is a separate issue. This is about misrepresentation. These photos have nothing to do with those girls who were kidnapped. These girls are from GuineaBissau, and the story I did was about something completely different. They have nothing to do with the terrible kidnappings. Can you imagine having your daughter's image spread throughout the world as the face of sexual trafficking? These girls have never been abducted, never been sexually trafficked. This is misrepresentation. I know these girls. I know these families, and they would be really upset to see their daughters' faces spread across the world and made the face of a terrible situation." (Vitale, 2014)

4 Citação no original: "I wanted to put a human face on conflict. But when I got there my story changed. Because I realized the way Africa is generally portrayed in mainstream media is either wars, famine or stories like this terrible abduction. You see the horrors or the other extreme, beautiful safaris and exotic animals. There's nothing in between. So it's ironic the story I was telling was that there is a beautiful world that lies between these two truths. Why don't we ever tell these stories that show the dignity and resilience of these people? And this is why I feel so enraged, because I was trying to not show them as victims. They are not victims. Using these images and portraying them as victims is not truthful. The story I did was a hopeful story." (VITALE, 2014)

5 Citação original, na tradução italiana do texto: "In generale, i corpi gravemente feriti che ci mostrano le fotografie pubblicate appartengono ad asiatici o ad africani. Si tratta di una consuetudine giornalistica che eredita la prassi secolare di mettere in mostra esseri umani esotici - vale a dire: colonizzati: dal XVI secolo fino all'inizio de XX, africani e abitanti di remoti paesi asiatici sono stati esibiti come animali di uno zoo nelle esposizioni etnologiche allestite a Londra, a Parigi e in altre capitali europee. (...) L'esibizione fotografica delle crudeltà inflitte a individui dalla pelle più scura in paesi esotici continua questo genere di offerta, ignorando le considerazioni che scoraggiano comportamenti simili quando le vittime della violenza sono nostre; poiché l'altro, anche quando non è nemico, è considerato soltanto come qualcuno da vedere, e non qualcuno che (come noi) vede."

6 Neste sentido, veja-se o ensaio de Robson Dutra (2012), "A infância, a guerra e a Nação", em que o estudioso reflecte em torno da infância como processo de narração da nação nas literaturas africanas de língua portuguesa.

7 Refiro-me por exemplo à problemática das crianças soldados, das vítimas de tráfico sexual e de órgãos, entre outras situações de carácter social, político e cultural que surgem em diferentes contextos, não apenas africanos.

8 Citação no original: “The world is a dark and ugly place, a lot of that ugliness and injustice is present in Africa, but we don't turn to literature to confirm that. The news is enough. What we turn to literature for is its ability to transport us beyond the headlines". 